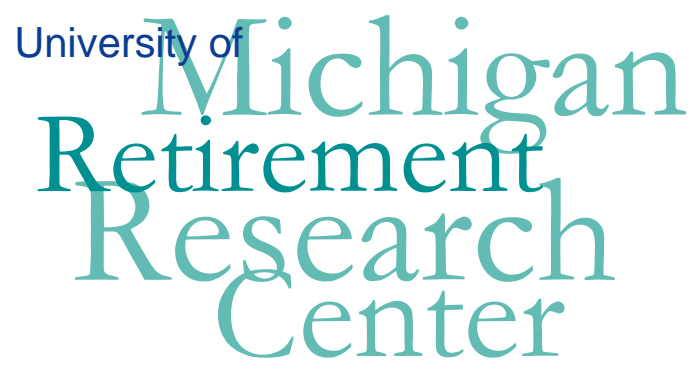

Working Paper WP 2005-095

\title{
The Impact of the 1972 Social Security Benefit Increase on Household Consumption
}

Melvin Stephens Jr.

\begin{tabular}{|l|l|l|}
\hline $\mathrm{M}$ & $\mathrm{R}$ & Project \#: UM04-05 \\
\hline $\mathrm{R}$ & $\mathrm{C}$ &
\end{tabular} 


\title{
"The Impact of the 1972 Social Security Benefit Increase on Household Consumption”
}

\author{
Melvin Stephens Jr. \\ Carnegie Mellon University and NBER
}

February 2005

\author{
Michigan Retirement Research Center \\ University of Michigan \\ P.O. Box 1248 \\ Ann Arbor, MI 48104
}

\section{Acknowledgements}

This work was supported by a grant from the Social Security Administration through the Michigan Retirement Research Center (Grant \# 10-P-98358-5). The findings and conclusions are solely those of the authors and should not be considered as representing the views of SSA, any agency of the Federal Government, or MRRC.

\section{Regents of the University of Michigan}

David A. Brandon, Ann Arbor; Laurence B. Deitch, Bingham Farms; Olivia P. Maynard, Goodrich; Rebecca McGowan, Ann Arbor; Andrea Fischer Newman, Ann Arbor; Andrew C. Richner, Grosse Pointe Park; S. Martin Taylor, Gross Pointe Farms; Katherine E. White, Ann Arbor; Mary Sue Coleman, ex officio 


\title{
The Impact of the 1972 Social Security Benefit Increase on Household Consumption
}

\author{
Melvin Stephens Jr.
}

\begin{abstract}
This paper examines the consumption response to the 1972 Social Security benefit increase. Nominal benefits were increased by 20 percent while annual cost of living adjustments (COLAs) were contemporaneously implemented and scheduled to begin in less than three years. Taken in isolation, this benefit increase could be viewed as a large and permanent increase in real Social Security benefits. However, the prevailing high rates of inflation that were the impetus for the COLA legislation may have caused households to view the permanent real benefit increase to be substantially less than 20 percent. Using data from the 1972-73 Survey of Consumer Expenditures, the results provide a mixed picture of the consumption impact of the benefit increase. Strictly nondurable consumption increases significantly at the time of the benefit increase. However, this increase does not persist. Furthermore, the likelihood of making any purchases from an array of durable good categories does not change throughout this period.
\end{abstract}

\section{Authors’ Acknowledgements}

This paper was supported by a grant from the Michigan Retirement Research Center. The data utilized in this paper were made available (in part) by the Inter-University Consortium for Political and Social Research. The data for SURVEY OF CONSUMER EXPENDITURES, 1972-73 were originally collected by the U.S. Department of Labor, Bureau of Labor Statistics. Neither the collectors of the original data nor the Consortium bears any responsibility for the analyses or interpretations presented here. The findings and conclusions expressed are solely those of the author and do not represent the views of the Social Security Administration, any agency of the Federal government, or the Michigan Retirement Research Center. 


\section{Introduction}

During the 1960s and 1970s, the United States witnessed an explosion in the number of individuals receiving benefits from government transfer programs. The number of Social Security recipients grew from nearly 15 million in 1960 to over 35 million in 1980. In 1960, less than one million families (3 million individuals) received benefits from Aid to Families with Dependent Children (AFDC). By 1980, 3.7 million families (10.7 million individuals) were AFDC recipients. In addition, a number of important programs started during this era. The Food Stamp program began in the early 1960s and had only 143,000 participants in 1962. By 1980, the Food Stamp program counted over 21 million participants. Both Medicare and Medicaid began in the mid-1960s and had, by 1980, over 25 million and 21 million enrollees, respectively. The Supplemental Security Insurance program began in 1974 and had roughly 4.2 million recipients by $1980 .^{1}$

A voluminous literature has emerged which examines the impact of these programs, as well as various programmatic changes, on labor supply behavior (See Blundell and MaCurdy (1999) for a review). However, very little attention has been paid to examining the impact of these programs on household well-being. To the extent that researchers have focused on well-being, studies have examined the likelihood that a program lifts a household above the federal poverty line (e.g., Engelhardt and Gruber 2004). However, the amount of research about how these programs affect household consumption is very scant.

This paper examines the impact of the 1972 Social Security benefit changes on household consumption. This law implemented a system of cost of living adjustments (COLAs) for Social Security benefits beginning in 1975. Prior to this amendment, Social Security benefits only were adjusted for inflation on an ad hoc basis which led to a decline in purchasing power between legislative actions. For example, between 1959 and 1970, the CPI rose by over 30 percent while benefits only were raised by 20 percent. While the nominal benefit increases in the pre-COLA era were permanent, the real benefit increases were not.

Not only did the law signed by President Nixon on July 1, 1972 provide for annual benefit indexing, it also that mandated benefits were to be increased by 20 percent starting

\footnotetext{
1 The figures presented in this paragraph are from Social Security Administration (2004).
} 
with the checks delivered in early October 1972. Since this benefit increase occurred with the promise of regular indexing to follow, the 1972 benefit increase potentially could be viewed by recipients as a permanent real benefit increase of 20 percent.

In a standard life-cycle/permanent income framework, a real Social Security benefit increase should result in a real consumption increase of the same amount. ${ }^{2}$ It is important to note, however, that this legislation was passed during a period when prices were rapidly rising. Following the first half of the 1960s when the annual rate of inflation was below two percent, annual inflation rates exceeded four percent from 1968 to 1971. Therefore, the nominal 20 percent increase in 1972 followed by COLA adjustments beginning nearly three years later may have resulted in households viewing the real benefit increase to be substantially less than 20 percent. Since the household's beliefs regarding the real benefit increase stemming from the legislation are the primary determinant of household behavior in a standard life-cycle/permanent income framework, the resulting consumption response may also have been far less than 20 percent.

In addition, the standard life-cycle/permanent income model predicts that consumption should respond at the time that the benefit increase is announced but should not respond when the benefit increase is implemented. ${ }^{3}$ Unfortunately, as discussed below, the available data do not permit an analysis of the response of non-durable consumption to the announcement of the benefit increase. The analysis presented here, as with most papers that examine the life-cycle/permanent income hypothesis, will test the prediction of the standard life-cycle/permanent income model that consumption should not change when the benefit increase is implemented.

Using data from the 1972-73 Survey of Consumer Expenditures (CEX), this paper examines the consumption response to the Social Security benefit increase in 1972. The results provide a mixed picture of the consumption impact of the benefit increase. Using

2 This response is true in terms of dollars. Of course, the household's income may not be entirely composed of Social Security income. If Social Security income were, for example, half of the household's income, then a 20 percent increase in real Social Security benefits would result in a 10 percent increase in household income and, correspondingly, a 10 percent increase in household consumption.

3 In a paper that examines the impact of the Social Security benefit increases on consumption using aggregate data, Wilcox (1989) finds that total retail sales experience a 1.4 percent permanent increase when contemporaneous benefits increase by 10 percent. 
the Diary Survey, strictly non-durable consumption increases significantly at the time of the benefit increase. This increase in spending does not persist. One possible explanation for both the consumption response at the time the benefit increase is implemented as well as the subsequent decline in consumption is liquidity constraints. However, the results when splitting the sample by whether or not the household is constrained are not consistent with this interpretation since a large and significant response is found for unconstrained households at the time benefits are increased. Using the Interview Survey, the probability of making any clothing, appliance, or vehicle purchases remains unchanged over this period. Overall, there appears to be only an immediate and small short-run response to the benefit increase that is inconsistent with both the standard life-cycle/permanent income model as well as the liquidity constrained version of the model.

The paper is set out as follows. Section 2 discusses the conditions surrounding the 1972 Social Security benefit increase. The data, the 1972-73 Survey of Consumer Expenditures, is then described in Section 3 followed by a discussion in Section 4 of the methodologies that are used to identify the impact of the benefit change on household consumption. Section 5 presents the results and Section 6 summarizes the findings.

\section{Background}

This section discusses the legislative and economic setting in which the 1972 Social Security benefit increases were implemented.

\section{Social Security Benefit Increases}

The public old age insurance system known as Social Security was established with the Social Security Act of 1935. Since that date, a number of changes to the program have occurred such as an expansion in eligibility for benefits, relaxation of the rules governing earned income while receiving benefits, and the introduction of disability benefits. In addition, a number of across the board benefit increases have been enacted in order to help Social Security benefit levels keep up with the rate of inflation. ${ }^{4}$

4 A legislative history of Social Security is given in Solomon (1986). 
The first benefit increase was in 1950 and was approximately 77 percent, with increases ranging from 100 percent for the lowest benefit levels to 50 percent for the highest benefit levels. ${ }^{5}$ Three additional benefit increases were enacted throughout the $1950 \mathrm{~s}$ with the last increase occuring in 1959. As prices grew very slowly during the first half of the 1960s, Social Security benefits were not increased again until 1965 when benefits were increased by 7 percent.

In the late 1960s and early 1970s, benefits increased as the rate of inflation climbed from a 1.6 percent annual rate in 1965 to over 5 percent in 1969 and 1970. Benefits were increased in 1968 (13 percent), 1970 (15 percent), and 1971 (10 percent) to keep up with the pace of inflation. Finally, in 1972, benefits were increased by 20 percent. Within the same bill, regular COLA adjustments were mandated to begin in 1975 whenever the Consumer Price Index increased by more than 3 percent in a year.

Figure 1 presents a monthly time-series of real Social Security benefit levels relative to the January 1966 benefit amount. ${ }^{6}$ As can be seen, the benefit increases that occurred during the 1960s essentially kept the average real benefit level constant throughout this period. The benefit increases in 1970 and 1971 actually begin to increase the real benefit levels since they exceed the rate of inflation over this period. The 20 percent benefit increase in 1972 was followed by period of rapid inflation that quickly eroded that benefit increase. In fact, rising price levels prior to the first planned COLA adjustment in 1975 led to an additional 11 percent permanent nominal benefit increase in mid-1974 so that real benefits would not be entirely eroded by the time of the scheduled increase in mid-1975.

An important issue from the point of view of households is how they viewed the benefit increases that occured in the early 1970s. If households viewed these benefit increases in the early 1970s as maintaining their long-run real purchasing levels - a view consistent with the ad hoc increases in the 1960s - then these benefit increases should not affect household consumption levels. On the other hand, the benefit increase in 1972 was also accompanied by the promise of future COLAs to maintain these benefits. However, these COLAs were

\footnotetext{
5 A history of Social Security benefit levels can be found in Solomon (1986) as well as on the Social Security web page at http://www.ssa.gov/OACT/HOP/hopi.htm.

6 The monthly CPI-U is used to deflated the benefit levels in Figure 1.
} 
not legislated to take place until nearly three years after the 20 percent increase. Any inflation in the intervening years could (and, in fact, did) erode the benefit levels. If not for the legislative action taken in 1974, the 1972 increase would have entirely diminished by the time that the first automatic COLA became effective. Thus, households likely did not view the 1972 increase as a real increase of 20 percent, but likely as some lower amount. Comparing the January 1972 benefit levels to the average real benefit levels in 1974 and beyond shows only a 7 to 8 percent real benefit increase. While it is not clear what household beliefs were regarding the amount of the real benefit increase, it is very likely they believed that the real benefit increase was far below 20 percent. ${ }^{7}$

\section{The Labor Supply Response to Social Security Benefit Increases}

The postwar era was marked by the slow decline of labor force participation by older men. While the decline was gradual during the 1950s and 1960s, the rate of decline accelerated during the late 1960s and early 1970s. These trends are presented in Figure 2 using data from the U.S. Bureau of Labor Statistics. It is important to note that these trends also exist, though to a lesser extent, for households outside of the typical retirement ages.

Among the reasons posited for the decline in labor force participation was the increasing benefit levels of Social Security. Boskin and Hurd (1984) suggest that Social Security benefits are an important reason for the decline in participation between 1969 and 1973 although they do not indicate the share of the decline directly attributable to the benefit increases. Other studies using the same data (the Retirement History Study) but different empirical methods find a very small role for the benefit increases in explaining the decline in work effort (Burtless and Moffitt 1985; Burtless 1986). ${ }^{8}$ These later studies are consistent with the long-run view of households shown in Figure 1: real benefits were not viewed as increasing nearly as dramatically as nominal benefits.

\footnotetext{
7 Moffitt (1987) estimates the magnitude of the Social Security wealth shocks using lagged Social Security wealth information over the period from 1950-1981. He shows that the magnitude of the wealth shocks for older households in the early 1970s is far smaller than the shocks that occurred in the earlier years.

8 A larger literature examined the impact of Social Security on retirement decisions using data prior to the 1970s. A number of these studies are cited in Moffitt (1987).
} 


\section{Data}

To analyze the impact of 1972 Social Security benefit increase on household consumption, this paper uses the 1972-73 Survey of Consumer Expenditures (CEX) which was collected by the Bureau of Labor Statistics. ${ }^{9}$ The CEX uses two survey instruments, the Interview Survey and the Diary Survey, with consumer units (CUs) chosen to participate in one but not for both of the components. ${ }^{10}$ "Big ticket" purchases such as washing machines and televisions that are more likely to be recalled over an extended period of time are the focus of the Interview Survey. Smaller purchases such as gasoline and gum that are unlikely to be remembered for too long are the focus of the Diary Survey. Both Surveys report a limited amount of household demographic information although this information covers the typical characteristics used in empirical research.

The Interview Survey data was collected by interviewing consumer units CUs for five consecutive quarters. The roughly 20,000 CUs in the Interview Survey began their interview periods either in the first quarter of 1972 or in the first quarter of 1973 . These CUs were then interviewed four additional times at quarterly interviews collecting expenditure information in three-month retrospective windows. The majority of these consumer units were interviewed in all five quarters of their survey period although some households did exit the sample during this period.

The Diary Survey interviewed each consumer unit during a two-week diary period. The Diary Surveys began in July 1972 and ended in June 1974 with consumer units, totaling slightly more than 23,000 in number, spread evenly throughout the survey period. ${ }^{11}$ Furthermore, households are also spread evenly across days within the month although the public use data only contains information on the month that each diary week began but does not include information on the day of the month.

The availability of information concerning the exact date of $\mathrm{CU}$ expenditures differs across the two surveys. All purchases recorded in the Diary Survey are entered into the

\footnotetext{
9 Prior to 1980, the CEX was not conducted on an on-going basis.

10 "Consumer Unit" and "Household" will be used interchangeably throughout the remainder of the paper.

11 An exception is in December of each year when households are oversampled.
} 
public use data along with an identifier for whether the purchase was made during the CU's first or second diary week. Since information on the CU's participation date are available, expenditures in the Diary Survey also can be assigned to a month and year of purchase. The public use Diary data, however, only contains information on a subset of expenditures even though households were instructed to list all expenses in their diaries. Specifically, food, alcohol, tobacco and smoking supplies, personal care products and services, nonprescription drugs, housekeeping supplies, gas, electricity, and other fuel, gasoline, motor oil, and related products, as well as miscellaneous items not covered by the Interview survey were listed on the public use data. However, this set of expenditures is nearly identical to the expenditures that comprise Lusardi's (1996) "strictly non-durable consumption" that has been in a number of papers that examine the consumption response to income changes using later CEX surveys. Thus, the findings from using the Diary data can be compared to results found elsewhere in the literature.

Unfortunately, the Interview Survey data does not provide information on the month and year of all purchases. Annual expenditures (for either 1972 or 1973) for a number of expenditure categories are reported. However, for a subset of expenditures, information on the purchase month and year is available for each item. Specifically, clothing, household textiles, major and minor appliances, and vehicles are available in separate files that include such date of purchase information. On the one hand, the combination of the two surveys allows a broad cross-section of consumption categories to be examined. On the other hand, only clothing and household textiles have been used in prior studies (although not necessarily always) that examine the consumption response to predictable income changes. A further complication is that these consumer durables are purchased infrequently which means that only a small share of CUs make such purchases during any given month or even calendar quarter. As such, the results for consumer durables will be presented but are not weighed as heavily as the findings from the Diary Survey.

Both surveys collect information on household income from family members ages 14 and older. Both datasets report total household income as well as the breakdowns of income sources for a limited number of sub-categories such as earned income, Social Security income, interest income, and welfare income. For the Diary Survey, this income information 
is reported for the twelve months prior to the last day of the diary survey period. For the Interview Survey, income data is reported by households at the end of the entire interview period and therefore corresponds to $\mathrm{CU}$ income for the year during which the $\mathrm{CU}$ participated in the survey. A non-negligible number of households do not report enough income to be deemed "complete income reporters" by the BLS. For these households, no income information is reported. Since this project analyzes the impact of the Social Security benefit increase, only complete income reporters are used in the analysis so that Social Security recipiency status can be determined.

The Diary Survey has 23,186 participants. Approximately ten percent of these households are incomplete income reporters. Another six percent of households do not complete one of the two weekly diaries or have invalid data for date of participation. After these households are deleted, 19,033 households remain with 4,714 of these households reporting the receipt of Social Security. The Interview Survey has 19,975 participants. Approximately five percent of these households are incomplete income reporters. Another five percent of households do not participate in the survey for the entire year. Dropping these households leaves 18,198 consumer units with 4,703 reporting the receipt of Social Security.

\section{Methodology}

This paper examines the prediction of the life-cycle/permanent income hypothesis that consumption should not respond when the Social Security benefit increase first appears in the checks of recipients. The identification strategies that are used to test this prediction must consider a number of factors due to the nature of the policy change, the collection of the data, and the information available in the public use dataset. These approaches and the tradeoffs between them are discussed here.

The first approach is to identify the consumption response simply from the time-series of the available data. The Social Security benefit increase (as well as the subsequent COLAs) was signed into law on July 1, 1972 and did not affect payments until the September checks (which are delivered at the beginning of October). Therefore, the time-series allows identification of both a response at the time of enactment as well as when the increases appear in the checks. Unfortunately, the Diary Survey does not begin until July 1972 which 
prevents the analysis of an enactment effect. And while the Interview Survey collects expenditure information beginning in January 1972, as discussed above it only contains date of purchase information primarily for durable goods. Therefore, examining the consumption response to the announcement of the benefit increase is not feasible.

The use of time-series identification is further complicated by the fact that the law provided an across the board 20 percent increase in benefits. Wilcox (1989) uses aggregate time-series to identify the consumption response to Social Security benefit increases from the mid-1960s to the mid-1980s. However, while Wilcox was able to identify the response from a number of benefit increases of varying magnitude, the current analysis has only one benefit increase to examine.

Nonetheless, the first approach is to use a difference-in-differences approach using Social Security recipient CUs as the treatment group and all other households as the control group. Obviously, there are a number of differences across households based on the family size, stage of the life-cycle, etc. that complicate such an identification strategy. To control for these effects, a set of indicators for family size, race, education, gender and age of the reference person, and marital status are included. Furthermore, no strong parametric assumptions are made regarding the demographic categories and consumption. A full set of indicators for each category of each demographic characteristic are included. E.g., a full range of age indicators (58) are included in the analysis. ${ }^{12}$

Therefore, the equation that is estimated is

$$
C_{i t}=X_{i t} \beta+S S_{i t} \gamma+\sum_{j=0}^{T} \tau_{j} \delta_{j}+\sum_{k=0}^{T}\left(\tau_{k} * S S_{i t}\right) \psi_{k}+\epsilon_{i t}
$$

where $C_{i t}$ is household $i$ 's consumption in quarter (or month) $t, X_{i t}$ are the demographic controls described above, $S S_{i t}$ is an indicator for whether or not individual $i$ is a Social Security recipient, $\tau_{j}$ are a set of quarter-year (month-year) indicators, and $\tau_{k} * S S_{i t}$ are the

12 The 1972-73 CEX includes six education categories, two race categories (black or non-black), two marital status categories (married or not married). As will be discussed below, top-coding of some of the information limits the analysis that can be performed. Family size is limited to seven categories with seven or more being the last category. Age of the reference person is top-coded at 75. Furthermore, the handful of CUs with a reference person under age 18 have been recoded to 18. Although these limits are not necessary for all of the analysis, they are imposed throughout to remain consistent. 
quarter-year (month-year) interactions with Social Security recipiency status. Therefore, the difference-in-difference consumption responses are found in the $\psi_{k}$ coefficients.

As (1) illustrates, the consumption response is identified by examining not only whether or not a sharp change in consumption occurs when the benefit increase occurs in October 1972, but whether this change is concentrated among Social Security recipients. Whereas Wilcox (1989) must infer that the increases in retail sales are due to Social Security recipients making increased purchases, the results here can be directly traced to Social Security recipients households.

In addition, while aggregate time-series data can examine the response of the representative consumer, it cannot determine whether, if any, heterogeneity in the consumption response exists. Using the 1972-73 CEX, such heterogeneity can be examined when using the available information. Unfortunately, limited information on characteristics that may be associated with the spending response are available. However, one such piece of information is the amount of investment and dividend income that the household received in the past twelve months. Since less than half of households report any such income, the consumption response is divided between households with and without investment income. This division of the response by investment income will also allow an investigation of the role that liquidity constraints may play in the consumption response to the benefit increase (Zeldes 1989).

One potential concern with this pure time-series approach is the composition of the control group. Household consumption patterns for younger households may not provide a valid control for Social Security recipient households even though a large number of demographic variables are included in the analysis. A solution to this problem would be to limit the sample to households that are at or beyond the Social Security normal retirement age.

Figure 3 shows the share of households receiving Social Security in the Interview Survey based upon the age of the reference person of the consumer unit. (A similar picture emerges for the Diary Survey participants.) As would be expected, the likelihood of receiving Social Security increases rapidly during the early sixties and remains relatively constant (given sampling error) for later ages. Furthermore, among households beyond the Social Security 
normal age, well over 80 percent of households are Social Security recipients. Hence, only a small (and likely select) control group remains if the analysis is restricted to this subset of households. Therefore, all households will be used as controls for this analysis and identification will rely the time-series change when benefits were increased in October 1972.

Another potential concern is that households may be induced to retire by the changes in Social Security benefits. If so, the composition of households used in the differencein-differences approach will be changing from the before to the after period and severely compromise the identification strategy. While the evidence discussed above regarding the labor supply effects of the Social Security benefit changes in the early 1970s is mixed, it does suggest that in the immediate period after the law change, the composition of households on Social Security probably did not change too dramatically.

In the 1972-73 CEX, the share of households receiving Social Security does not change too much over the sample period. Figure 4 presents the time-series share of households in the Diary Survey receiving any Social Security in the past twelve months. Since these households are asked these questions when they are in the Diary Survey, it provides a nearly current time-series of the share of households receiving Social Security over this period. As the Figure illustrates, the share of households receiving these benefits shows no appreciable change over this period. Thus, while the labor supply responses are a concern, they do not appear to have caused any sharp changes in the share of households receiving Social Security in the period immediately surrounding the 1972 benefit increase.

An additional identification approach is based on the fact that while all Social Security recipients had their benefits increase by 20 percent, this change to not correspond to a 20 percent increase in total household income. This approach is complicated by the reasons why the share of Social Security in total income varies across households. Households that do not rely entirely upon Social Security for income are, on average, higher income households. In addition, these households tend to still be working. Therefore, this source of variation may be correlated with a number of factors that are associated with differences in consumption for reasons unrelated to the Social Security benefit increase. Nevertheless, it does supply an additional source of variation to be exploited. 
Figure 5 illustrates the average share of Social Security income in total income among households that have Social Security in the Interview Survey. Each set of bars corresponds to a range in the rounded up share of income from Social Security. For example, 0.2 refers to households with a share of income from Social Security that is greater than 0.1 but less than or equal to 0.2. Thus, as can be seen in the Figure, 12.7 percent of households with Social Security receive between 10 and 20 percent of their income from Social Security. The open bars in Figure 5 indicate that there is a tremendous amount of variation in this share across households that are receiving Social Security.

Additional issues are raised when using this second source of variation. First, consumer units report income for the past twelve months and not on a finer scale. In the Diary Survey, since very few households stop collecting benefits after becoming a recipient, CUs reporting collecting Social Security benefits in the last twelve months are highly likely to be current recipients. In the Interview Survey, however, we can only be confident that households receive benefits at the end of the interview year (calendar year) but cannot be sure when households started collecting benefits.

Second, since the date of benefit receipt cannot be determined, it is difficult to determine the share of total household income that is due to Social Security benefits. For older households past the Social Security normal retirement age, it may not be too strong an assumption that income is relatively constant throughout the year and therefore using the share of Social Security income in total income would not present a problem. The solid bars in Figure 5 illustrate the distribution of the share of Social Security of total income for households where the reference person is older than 65. Social Security provides a higher share of income for these households relative to all households receiving Social Security, but there still remains a large amount of heterogeneity.

Third, an important data issue further complicates this approach. The original public use datasets for the $1972-73$ CEX were top-coded. ${ }^{13}$ This top-code does not prevent one from knowing whether or not the household received any income from a particular source. However, the amount of the income received from that source is not available.

13 In addition, to help protect the identity of households, the data were also "bottom-coded". 
This top-code affects roughly one-sixth of all Social Security recipient CUs (among those CUs deemed complete income reporters).

Fortunately, the Bureau of Labor Statistics released subsequent versions of the 1972-73 CEX that did not have top-codes present. All of this data is available for the Interview Survey. However, this information is only available for the first year of the Diary Survey. Thus, only limited analysis can be performed using Diary Survey. However, since the benefit increase occurs during the year that the non-top coded Diary Survey data is available, this approach can be applied to both CEX survey instruments.

\section{Results}

The results in this section are presented separately for the two components of the 197273 CEX. As discussed above, the Diary Survey results are the ones that most readily can be translated to the consumption literature. As such, these results will be presented first and receive the majority of the attention. However, since Wilcox (1989) finds that the consumption response to Social Security benefit increases is larger for durable good retailers, the durable good results from the Interview Survey are also presented.

\section{Results from the Diary Survey}

Figure 6 presents the estimated $\psi_{k}$ coefficients, along with the 95 percent confidence intervals, from using all of the CUs to estimate equation (1). ${ }^{14}$ The dependent variable is the log of total expenditure reported in the public use Diary Survey over the entire two-week diary period. ${ }^{15}$ As discussed above, this consumption measure is very comparable to the "strictly non-durable" consumption measure used in the literature. The time period variables, $\tau_{k}$, refer to the quarter and year of expenditure for the second of the CUs two diary weeks with the third quarter of 1972 being the excluded category. Thus, the $\psi_{k}$ coefficients are the difference-in-difference coefficients for total two-week diary expenditure using the

\footnotetext{
14 The full set of regression results for this regression are presented in Table 1. The standard errors are robust to heteroskedasticity. All analyses reported in this paper use the CEX sampling weights.

15 The use of log expenditure allows the coefficients to be roughly interpreted as percentage changes in expenditure. Since less than 0.6 percent of households report no expenditures over the two-week period, the log specification has a very minor effect on the sample composition.
} 
third quarter of 1972 as the "before" period relative to all other quarters and non-Social Security CUs as the control group.

The results in Figure 6 indicate that there is a significant increase in expenditures of roughly 15 percent (with a p-value of less than 0.01) among Social Security recipients in the quarter when their benefits were increased. This finding is inconsistent with the basic life-cycle/permanent income hypothesis which would predict that there should be no consumption response at the time the benefit increase is implemented. The magnitude of the consumption increase is somewhat larger than would be expected given the discussion above in the background section. That discussion suggests that the benefit increase was likely seen as increasing real benefits by far less than 20 percent. Figure 4 indicates that the impact of the benefit increase on real total household income was likely only half the size of the impact on real benefits. Given these facts, the 15 percent result is likely much larger than would be expected.

Wilcox (1989) finds that total retail sales experience a 1.4 percent permanent increase when contemporaneous benefits increase by 10 percent. For the 20 percent benefit increase in 1972, this result implies a roughly 3 percent permanent increase in retail sales. However, Wilcox's finding is for the aggregate economy while the results reported here isolate the effect for Social Security recipient households. Given that roughly 25 percent of the weighted CEX sample reports the receipt of Social Security, one might expect a 12 percent increase in expenditure. The short-run effect found here is comparable to the prediction from Wilcox's results.

One possibility is that the result in Figure 6 for the fourth quarter of 1972 is coincidentally due to one or a small number of outliers. If so, then we would expect that an outlier would impact one of the months during the quarter but not all three months since households can only be assigned to a single month in the Diary Survey. Figure 7 presents estimates of equation (1) where the $\tau_{k}$ are defined as the month and year in which the second diary week begins as opposed to using the quarterly information as in Figure $6 .{ }^{16}$ Figure 7 shows that expenditures increased by nearly 15 percent between September and

\footnotetext{
16 Given the large number of coefficients for the monthly analysis, the full set of results corresponding to Figure 7 are not presented here. However, these results are available from the author upon request.
} 
October of 1972. The coefficient for October 1972 is marginally significant. The estimated effect for November is strongly significant while that for December is economically large but statistically insignificant. The monthly results strengthen the case that the response is due to the increase of Social Security benefits.

The remaining quarters of Figure 6 (and months of Figure 7), however, are not consistent with a permanent increase in consumption due to the benefit increase. Rather than remain permanently increased relative to the "before" period, none of the quarterly coefficients nor of the monthly coefficients are statistically significant. Thus, it does not appear that there were any effects of on consumption beyond the first quarter in which the benefit increase was implemented.

Why would there not be any long-run effect on consumption? One possibility is that households viewed the benefit increase and subsequent COLAs as simply maintaining their real benefit purchasing power over the long-run and did not view the 20 percent increase as a real benefit increase. However, this explanation is inconsistent with the large initial increase in consumption immediately following the benefit increase. Another possibility is that households are very myopic, assumed that the benefit increase was a real increase of 20 percent and that the COLAs, although not due to again take place for nearly three years, would keep real benefits at these new, higher levels. While inflation did erode away nearly half of the real increase by the middle of 1973 (see Figure 1), a story of pure myopia would suggest that this increase would decline as the price level increased. Instead, this increase appears to disappear entirely in the first quarter of 1973.

A third possibility, although very much related to the previous point, is that households are liquidity constrained. While they would like to smooth real consumption between nominal benefit increases, their lack of access to the capital markets prevents them from doing so. This possibility can also reconcile the finding that consumption responds when the benefit increase is implemented. Of course, households can always save their income. Thus, if a nominal benefit increase overshoots the long-run real level and is only increased once it is somewhat below the long-run real level, households could save in the months following the nominal increase to raise spending in the periods immediately before the next increase. Thus, it seems highly unlikely that such a story can explain the pattern found here. 
Figures 8 and 9 explore whether there is heterogeneity in the response to associated with differences in investment income. ${ }^{17}$ Specifically, the estimates examine whether or not the consumption response differs for households reporting any investment income in the past twelve months against those households that do not have any investment income. The estimation is performed through modifying equation (1) by including separate $\tau_{k}$ indicators for households with and with investment income. In addition, the $\tau_{k} * S S_{i t}$ interactions are entered separately for both of the investment income groups. Figure 8 reports the coefficients on these interactions for households with investment income while Figure 9 reports the interaction coefficients for households who do not report any investment income.

These results are further evidence against a pure liquidity constrained interpretation of the results. For households with investment income (unconstrained households), the increase in consumption is large and significant in the quarter when benefits are increased. In subsequent quarters, the coefficients are all positive but none are statistically significant. For households without any investment income (constrained households), the initial increase in consumption is nearly significant $(\mathrm{t}=1.92)$, and roughly the same in magnitude as the increase for households with investment income. Consumption in subsequent quarters is opposite in sign, although none of the coefficients is statistically significant. On the one hand, although imprecisely measured, the contrast between the patterns in Figures 8 and 9 for the long-run impact of the benefit increase on consumption is consistent with heterogeneity in the response caused by liquidity constraints. However, the large and significant consumption response for the unconstrained households at the time of the benefit increase is inconsistent with the life-cycle/permanent income model since these unconstrained households should have only responded at the time the benefit increase was announced.

To further explore the response to the Social Security benefit increase, the second identification strategy is also implemented. Under this strategy, the sample is limited to only Social Security beneficiaries. Although all of these households receive the same

$\overline{17}$ The full set of results for the specifications presented in Figures 8 and 9 are shown in Table 2. 
20 percent benefit increase, the impact of the benefit increase on total household income depends on Social Security's share of household income. Thus, differences in the response to the benefit increase are allowed to vary by the household's share.

As discussed above, non top-coded income data is only available for the first full year of the Diary Survey which spans July 1972 to June 1973. In addition, the strategy is further complicated since the twelve month retrospective reporting window for income means that the reported share of income from Social Security may not be the same as the share at the date of the survey. To alleviate this concern (to some degree), the sample is also limited to households where the reference person is over age 65 . The remaining number of observations is 1,418. To use a parsimonious model that recognizes the limits of the sample size, the analysis divides the response between households with a high share of income from Social Security and those with a low share from Social Security. ${ }^{18}$

Figures 10 and 11 report the coefficients for the low share and high share groups, respectively. ${ }^{19}$ These estimates are not the difference-in-difference results that were presented above. Rather, these are time-series of expenditures for each group. For both low and high share households, consumption increases in the fourth quarter of 1972 which suggests that the initial response found in Figure 6 is spread throughout Social Security CUs. The response continues to be higher for low share CUs for an additional quarter but then declines by the second quarter of 1973. For the high share households, the response decreases following the initial response. ${ }^{20}$ Thus, the difference-in-difference response would suggest, if anything, that the response is somewhat more persistent for the low share CUs. However, as with the investment income results above, these differences are not measured precisely.

\footnotetext{
18 A high share of income from Social Security is defined as having more than 60 percent of income from Social Security. Within this sample, both the mean and median of this share is 61 percent.

19 The full set of results for the specifications presented in Figures 10 and 11 are shown in Table 3.

20 The responses for these two groups are somewhat similar to those for the full sample when split by investment income. Cross-tabulations of the indicator for having any investment income and for being a high share $\mathrm{CU}$ indicates that two thirds of the high share households have no investment income. Thus, the similarity in the findings is not too surprising.
} 
The expenditures reported in the Interview Survey are mainly durable good purchases that typically are not analyzed when examining the consumption response to income changes. However, since Wilcox (1989) finds that the largest response to the Social Security benefit increases in aggregate time-series data is among durable good retailers, it is important to examine expenditures on these types of goods. One problem with durable good purchases is the discreteness of their purchases. At the quarterly frequencies found in the data, clothing purchases are made in less than 90 percent of quarterly observations, appliances purchases occur in 43 percent of quarterly observations, and vehicle purchases are made in 10 percent of the quarterly observations. As such, the analysis is limited to examining whether or not households made any purchase of that type during the calendar quarter in question.

Figure 12 estimates (1) using an indicator for whether or not the CU made clothing purchases during the quarter. ${ }^{21}$ As with the analysis in Figures 6 through 9 , the control group is all non-Social Security recipient households. Thus, the reported coefficients are the response of Social Security households relative to non-recipient households. The results from estimating linear probability models are reported in the Figure. Since households are observed for four quarters, the standard errors are adjusted to allow for arbitrary forms of serial correlation within the consumer unit across quarters. Relative to the base period of the first quarter of 1972, the probability of making any clothing purchases remains relatively constant over this period. There is a significant decline in clothing expenditures in the third quarter of 1972 that rebounds in the following quarter. Since this upward shift is contemporaneous with the increase in benefits, it is may be tempting to attribute this change to the benefit increase. However, given the overall time path of purchases, there is little evidence that clothing expenditures were affected by the benefit increase.

The estimates using appliance purchases, either major or minor appliances, are presented in Figure 13. These results show no evidence of an appliance expenditure response to the benefit increase. If anything, the response during the fourth quarter of 1972 is very

21 The full set of results for the specifications presented in Figures 12 through 14 are shown in Table 4 . 
negative. However, a response of a similar magnitude is also found for the fourth quarter of 1973. As shown in the middle column of Table 4, large increases in appliance purchases are found for the control group during the fourth quarter, coinciding with the holiday season. As such, when combined with the seasonal response for the control households, Social Security households also show a seasonal increase in appliance expenditures in the fourth quarter but not to the degree of the control households. Overall, the seasonal patterns of appliance expenditure strongly dominate the results and suggest little, if any, impact of the benefit increase on appliance expenditures.

Figure 14 presents the results for vehicle purchases. The results follow a similar pattern as those shown for clothing purchases in Figure 12. Expenditures decline in the third quarter of 1972 although this change is not statistically significant. The point estimate increases during the fourth quarter of 1972 but is again insignificant. In fact, all of the point estimates for car purchases are insignificant. As with the other durable good categories in the Interview Survey, vehicle purchases show no evidence of a response to the 1972 Social Security benefit increase.

\section{Summary}

This paper examines the consumption response to the 1972 Social Security benefit increase. Nominal benefits were increased by 20 percent while annual cost of living adjustments were contemporaneously implemented and scheduled to begin in less than three years. Thus, this benefit increase could be viewed as a permanent, real increase in benefits. However, as discussed above, the actual long-run increase in real benefits was not only much less than 20 percent, but it is highly likely that households viewed the real increase to be substantially less than 20 percent at the time of the benefit increase.

Using data from the 1972-73 Survey of Consumer Expenditures, the results provide a mixed picture of the consumption impact of the benefit increase. Using the Diary Survey, strictly non-durable consumption increases significantly at the time of the benefit checks are increased. However, this increase in consumption does not persist. Using the Interview Survey, the probability of making any clothing, appliance, or vehicle purchases remains unchanged over this period. 
The results found here are difficult to reconcile with the standard life-cycle/permanent income model. Since the benefit increase was announced three months before it took effect, there should not be a consumption response at the time when Social Security checks were increased. Contrary to this prediction, consumption increases when the benefit levels are increased. One possible explanation for both the consumption response at the time the benefit increase is implemented as well as the subsequent decline in consumption is liquidity constraints. However, the results when splitting the sample by whether or not the household is constrained are not consistent with this interpretation since a large and significant response is found for unconstrained households at the time benefits are increased. Furthermore, the liquidity constrained model (as well as the standard model) would predict a persistent increase on consumption following the initial increase. Therefore, aside from the increased spending in the fourth quarter of 1972 being a statistical anomaly, the results are neither consistent with a standard life-cycle/permanent income model nor with a model modified to incorporate liquidity constraints. 


\section{References}

Blundell, Richard and Thomas MaCurdy (1999) "Labor Supply: A Review of Alternative Approaches," in Handbook of Labor Economics, Volume 3A, ed. Orley C. Ashenfelter and David Card. Amsterdam: Elsevier Science B.V..

Burtless, Gary (1986) "Social Security, Unanticipated Benefit Increases, and the Timing of Retirement," The Review of Economic Studies, 53, 5, 781-805.

Burtless, Gary and Robert A. Moffitt (1985) "The Joint Choice of Retirement Age and Postretirement Hours of Work," Journal of Labor Economics, 3, 2, 209-36.

Englehardt, Gary V. and Jonathan Gruber (2004) "Social Security and the Evolution of Elderly Poverty," National Bureau of Economic Research Working Paper \#10466.

Hurd, Michael D. and Michael J. Boskin (1984) "The Effect of Social Security on Retirement in the Early 1970s," The Quarterly Journal of Economics, 99, 4, 767-790.

Lusardi, Annamaria (1996) "Permanent Income, Current Income, and Consumption: Evidence from Two Panel Data Sets," Journal of Business and Economic Statistics, 14, $1,81-90$.

Moffitt, Robert A. (1987) "Life-Cycle Labor Supply and Social Security: A Time-Series Analysis," in Work, Health, and Income Among the Elderly, ed. Gary Burtless. Washington: Brookings Institution.

Social Security Administration (2004) Annual Statistical Supplement to the Social Security Bulletin, 2003. Washington: Social Security Administration

Solomon, Carmen D. (1986) "Major Decisions in the House and Senate Chambers on Security: 1935-1985," CRS Report for Congress.

Wilcox, David W. (1989) "Social Security Benefits, Consumption Expenditure, and the Life Cycle Hypothesis," Journal of Political Economy, 97, 2, 288-304.

Zeldes, Stephen P. (1989) "Consumption and Liquidity Constraints: An Empirical Investigation," Journal of Political Economy, 97, 2, 305-346. 
Table 1 - Impact of the 1972 Social Security Benefit Increase On Strictly Non-Durable Consumption Diary Survey

\begin{tabular}{lcc}
\hline Independent Variable & Coefficient & Standard Error \\
\hline Household size=2 & 0.485 & $(0.023)$ \\
Household size=3 & 0.663 & $(0.025)$ \\
Household size=4 & 0.769 & $(0.026)$ \\
Household size=5 & 0.872 & $(0.027)$ \\
Household size=6 & 0.937 & $(0.030)$ \\
Household size>6 & 1.014 & $(0.034)$ \\
Married Household Head & 0.003 & $(0.027)$ \\
Male Household Head & 0.264 & $(0.024)$ \\
Black Household Head & -0.211 & $(0.020)$ \\
Head education: 9-11 years & 0.136 & $(0.017)$ \\
Head education: 12 years & 0.221 & $(0.016)$ \\
Head education: 13-15 years & 0.284 & $(0.018)$ \\
Head education: 16+ years & 0.310 & $(0.017)$ \\
Head education: None, N/A & -0.232 & $(0.062)$ \\
Quarter 4, 1972 & -0.035 & $(0.023)$ \\
Quarter 1, 1973 & 0.024 & $(0.022)$ \\
Quarter 2, 1973 & -0.029 & $(0.023)$ \\
Quarter 3, 1973 & 0.003 & $(0.022)$ \\
Quarter 4, 1973 & 0.017 & $(0.021)$ \\
Quarter 1, 1974 & 0.039 & $(0.021)$ \\
Quarter 2, 1974 & 0.032 & $(0.022)$ \\
Social Security Recipient & -0.020 & $(0.040)$ \\
Quarter 4, 1972 * SS Recipient & 0.152 & $(0.050)$ \\
Quarter 1, 1973 * SS Recipient & 0.041 & $(0.051)$ \\
Quarter 2, 1973 * SS Recipient & -0.022 & $(0.054)$ \\
Quarter 3, 1973 * SS Recipient & -0.023 & $(0.050)$ \\
Quarter 4, 1973 * SS Recipient & 0.037 & $(0.049)$ \\
Quarter 1, 1974 * SS Recipient & 0.016 & $(0.051)$ \\
Quarter 2, 1974 * SS Recipient & 0.009 & $(0.049)$ \\
\hline
\end{tabular}

Note: These regressions also include a full set of individual age indicators.

The excluded time period is quarter 3, 1972.

White heteroskedasticity-robust standard errors are reported.

$\mathrm{N}=18,928$ 
Table 2 - Impact of the 1972 Social Security Benefit Increase On Strictly Non-Durable Consumption By Having Interest Income - Diary Survey

\begin{tabular}{|c|c|c|}
\hline Independent Variable & Coefficient & Standard Error \\
\hline Household size $=2$ & 0.487 & $(0.023)$ \\
\hline Household size $=3$ & 0.668 & $(0.025)$ \\
\hline Household size $=4$ & 0.773 & $(0.026)$ \\
\hline Household size $=5$ & 0.881 & $(0.027)$ \\
\hline Household size $=6$ & 0.947 & $(0.030)$ \\
\hline Household size $>6$ & 1.029 & $(0.034)$ \\
\hline Married Household Head & -0.006 & $(0.027)$ \\
\hline Male Household Head & 0.262 & $(0.023)$ \\
\hline Black Household Head & -0.192 & $(0.020)$ \\
\hline Head education: 9-11 years & 0.124 & $(0.017)$ \\
\hline Head education: 12 years & 0.200 & $(0.016)$ \\
\hline Head education: $13-15$ years & 0.256 & (0.018) \\
\hline Head education: $16+$ years & 0.272 & $(0.018)$ \\
\hline Head education: None, N/A & -0.217 & $(0.062)$ \\
\hline Q4, $1972 *$ Has Interest Income & -0.017 & $(0.036)$ \\
\hline Q1, $1973 *$ Has Interest Income & 0.035 & $(0.031)$ \\
\hline Q2, 1973 * Has Interest Income & -0.012 & $(0.033)$ \\
\hline Q3, $1973 *$ Has Interest Income & -0.009 & $(0.032)$ \\
\hline Q4, 1973 * Has Interest Income & 0.030 & $(0.031)$ \\
\hline Q1, 1974 * Has Interest Income & 0.012 & $(0.031)$ \\
\hline Q2, 1974 * Has Interest Income & 0.019 & $(0.033)$ \\
\hline No Interest Income & -0.085 & $(0.032)$ \\
\hline Q4, 1972 * No Interest Income & -0.043 & $(0.030)$ \\
\hline Q1, 1973 * No Interest Income & 0.016 & $(0.030)$ \\
\hline Q2, $1973 *$ No Interest Income & -0.039 & $(0.031)$ \\
\hline Q3, 1973 * No Interest Income & 0.008 & $(0.029)$ \\
\hline Q4, 1973 * No Interest Income & 0.011 & $(0.027)$ \\
\hline Q1, 1974 * No Interest Income & 0.052 & $(0.028)$ \\
\hline Q2, 1974 * No Interest Income & 0.035 & $(0.029)$ \\
\hline Social Security Recipient & -0.036 & $(0.052)$ \\
\hline Q 4, 1972* SS Recip*Has Int Inc & 0.174 & $(0.070)$ \\
\hline Q 1,1973 * SS Recip*Has Int Inc & 0.103 & $(0.066)$ \\
\hline Q 2,1973 * SS Recip*Has Int Inc & 0.013 & $(0.073)$ \\
\hline Q 3, 1973 * SS Recip*Has Int Inc & 0.085 & $(0.066)$ \\
\hline Q 4, 1973 * SS Recip*Has Int Inc & 0.114 & $(0.063)$ \\
\hline Q 1, 1974* SS Recip*Has Int Inc & 0.091 & $(0.066)$ \\
\hline Q 2, 1974* SS Recip*Has Int Inc & 0.072 & $(0.067)$ \\
\hline SS Recipient ${ }^{\star}$ No Interest Income & 0.021 & $(0.074)$ \\
\hline Q 4, 1972* SS Recip*No Int Inc & 0.137 & $(0.071)$ \\
\hline Q 1, 1973 * SS Recip*No Int Inc & -0.008 & $(0.075)$ \\
\hline Q 2, 1973 * SS Recip*No Int Inc & -0.051 & $(0.078)$ \\
\hline Q 3, 1973 * SS Recip*No Int Inc & -0.085 & $(0.072)$ \\
\hline Q 4, 1973 * SS Recip*No Int Inc & -0.022 & $(0.071)$ \\
\hline Q 1,1974 * SS Recip*No Int Inc & -0.040 & $(0.075)$ \\
\hline Q 2, 1974 * SS Recip*No Int Inc & -0.027 & $(0.071)$ \\
\hline
\end{tabular}




\begin{tabular}{lcc}
\hline $\begin{array}{r}\text { Table } 3 \text { - Impact of the } \\
\text { On Strictly }\end{array}$ Non-Durable Consumption \\
By Social Security Share of Total Income & - Diary Survey \\
\hline Independent Variable & Coefficient & Standard Error \\
\hline Household size=2 & 0.660 & $(0.069)$ \\
Household size=3 & 1.092 & $(0.097)$ \\
Household size=4 & 1.028 & $(0.126)$ \\
Household size=5 & 1.368 & $(0.174)$ \\
Household size=6 & 1.130 & $(0.153)$ \\
Household size>6 & 1.475 & $(0.169)$ \\
Married Household Head & -0.178 & $(0.085)$ \\
Male Household Head & 0.259 & $(0.075)$ \\
Black Household Head & -0.158 & $(0.080)$ \\
Head education: 9-11 years & 0.111 & $(0.059)$ \\
Head education: 12 years & 0.242 & $(0.057)$ \\
Head education: 13-15 years & 0.271 & $(0.089)$ \\
Head education: 16+ years & 0.356 & $(0.074)$ \\
Head education: None, N/A & -0.112 & $(0.115)$ \\
Q4, 1972 * Low Share & 0.161 & $(0.068)$ \\
Q1, 1973 * Low Share & 0.172 & $(0.067)$ \\
Q2, 1973 * Low Share & 0.005 & $(0.086)$ \\
High Share of Income from S.S. & -0.170 & $(0.083)$ \\
Q4, 1972 * High Share & 0.210 & $(0.085)$ \\
Q1, 1973 * High Share & 0.065 & $(0.091)$ \\
Q2, 1973 * High Share & -0.035 & $(0.092)$ \\
\hline
\end{tabular}

Note: This sample is restricted to households over age 65 that receive Social Security.

Low Share is households with 60 percent or less of total income from Social Security.

High Share is households with more than 60 percent of total income from Social Security.

The excluded time period is quarter 3, 1972.

These regressions also include a full set of individual age indicators.

White heteroskedasticity-robust standard errors are reported.

$\mathrm{N}=1,404$ 


\section{Table 4 - Impact of the 1972 Social Security Benefit Increase On Durable Good Consumption Interview Survey}

\begin{tabular}{|c|c|c|c|c|c|c|}
\hline \multirow[b]{3}{*}{ Independent Variable } & \multicolumn{6}{|c|}{ Dependent Variable } \\
\hline & \multicolumn{2}{|c|}{$\begin{array}{l}\text { Any Clothing } \\
\text { Purchase }\end{array}$} & \multicolumn{2}{|c|}{$\begin{array}{c}\text { Any Appliance } \\
\text { Purchase }\end{array}$} & \multicolumn{2}{|c|}{$\begin{array}{l}\text { Any Vehicle } \\
\text { Purchase }\end{array}$} \\
\hline & Coeff. & Std. Err. & Coeff. & Std. Err. & Coeff. & Std. Err. \\
\hline Household size=2 & 0.068 & $(0.007)$ & 0.024 & $(0.005)$ & 0.003 & $(0.004)$ \\
\hline Household size=3 & 0.097 & $(0.008)$ & 0.044 & $(0.006)$ & 0.032 & $(0.005)$ \\
\hline Household size=4 & 0.112 & $(0.008)$ & 0.049 & $(0.007)$ & 0.047 & $(0.006)$ \\
\hline Household size $=5$ & 0.112 & $(0.009)$ & 0.056 & $(0.008)$ & 0.058 & $(0.007)$ \\
\hline Household size=6 & 0.114 & $(0.009)$ & 0.064 & $(0.009)$ & 0.070 & $(0.008)$ \\
\hline Household size>6 & 0.114 & $(0.010)$ & 0.062 & $(0.010)$ & 0.071 & $(0.009)$ \\
\hline Married Household Head & 0.077 & $(0.010)$ & 0.051 & $(0.006)$ & 0.008 & $(0.005)$ \\
\hline Male Household Head & -0.083 & $(0.009)$ & 0.005 & $(0.005)$ & 0.041 & $(0.004)$ \\
\hline Black Household Head & -0.039 & $(0.006)$ & -0.028 & $(0.005)$ & -0.044 & $(0.004)$ \\
\hline Head education: 9-11 years & 0.031 & $(0.006)$ & 0.002 & $(0.005)$ & 0.006 & $(0.004)$ \\
\hline Head education: 12 years & 0.052 & $(0.005)$ & 0.013 & $(0.004)$ & 0.002 & $(0.003)$ \\
\hline Head education: $13-15$ years & 0.058 & $(0.006)$ & 0.018 & $(0.005)$ & 0.000 & $(0.004)$ \\
\hline Head education: $16+$ years & 0.067 & $(0.005)$ & 0.024 & $(0.005)$ & -0.022 & $(0.004)$ \\
\hline Head education: None, N/A & -0.001 & $(0.011)$ & -0.036 & $(0.005)$ & -0.009 & $(0.005)$ \\
\hline Quarter 2, 1972 & 0.018 & $(0.004)$ & 0.007 & $(0.006)$ & 0.008 & $(0.006)$ \\
\hline Quarter 3, 1972 & 0.033 & $(0.004)$ & 0.033 & $(0.007)$ & 0.014 & $(0.006)$ \\
\hline Quarter 4, 1972 & 0.067 & $(0.004)$ & 0.095 & $(0.007)$ & 0.003 & $(0.006)$ \\
\hline Quarter 1, 1973 & -0.013 & $(0.005)$ & 0.009 & $(0.006)$ & 0.015 & $(0.006)$ \\
\hline Quarter 2, 1973 & 0.013 & $(0.005)$ & 0.039 & $(0.007)$ & 0.018 & $(0.006)$ \\
\hline Quarter 3, 1973 & 0.014 & $(0.005)$ & 0.043 & $(0.007)$ & 0.015 & $(0.006)$ \\
\hline Quarter 4, 1973 & 0.051 & $(0.005)$ & 0.086 & $(0.007)$ & -0.010 & $(0.006)$ \\
\hline Social Security Recipient & -0.002 & $(0.010)$ & 0.017 & $(0.008)$ & 0.001 & $(0.007)$ \\
\hline Quarter 2, 1972 * SS Recipient & -0.015 & $(0.010)$ & 0.001 & $(0.010)$ & 0.003 & $(0.008)$ \\
\hline Quarter 3, 1972 * SS Recipient & -0.028 & $(0.011)$ & 0.007 & $(0.011)$ & -0.012 & $(0.008)$ \\
\hline Quarter 4, 1972 * SS Recipient & 0.000 & $(0.010)$ & -0.037 & $(0.012)$ & 0.010 & $(0.008)$ \\
\hline Quarter 1, 1973 * SS Recipient & 0.005 & $(0.013)$ & 0.003 & $(0.010)$ & -0.003 & $(0.009)$ \\
\hline Quarter 2, 1973 * SS Recipient & 0.001 & $(0.012)$ & -0.016 & $(0.011)$ & -0.007 & $(0.009)$ \\
\hline Quarter 3, 1973 * SS Recipient & -0.010 & $(0.013)$ & 0.000 & $(0.011)$ & -0.005 & $(0.009)$ \\
\hline Quarter 4, 1973 * SS Recipient & -0.002 & $(0.012)$ & -0.040 & $(0.011)$ & 0.012 & $(0.008)$ \\
\hline
\end{tabular}

Note: These regressions also include a full set of individual age indicators.

The excluded time period is quarter 1, 1972.

Standard errors adjusted for arbitrary forms of serial correlation are reported.

$\mathrm{N}=18,198 ; \mathrm{N}^{\star} \mathrm{T}=72,792$ 


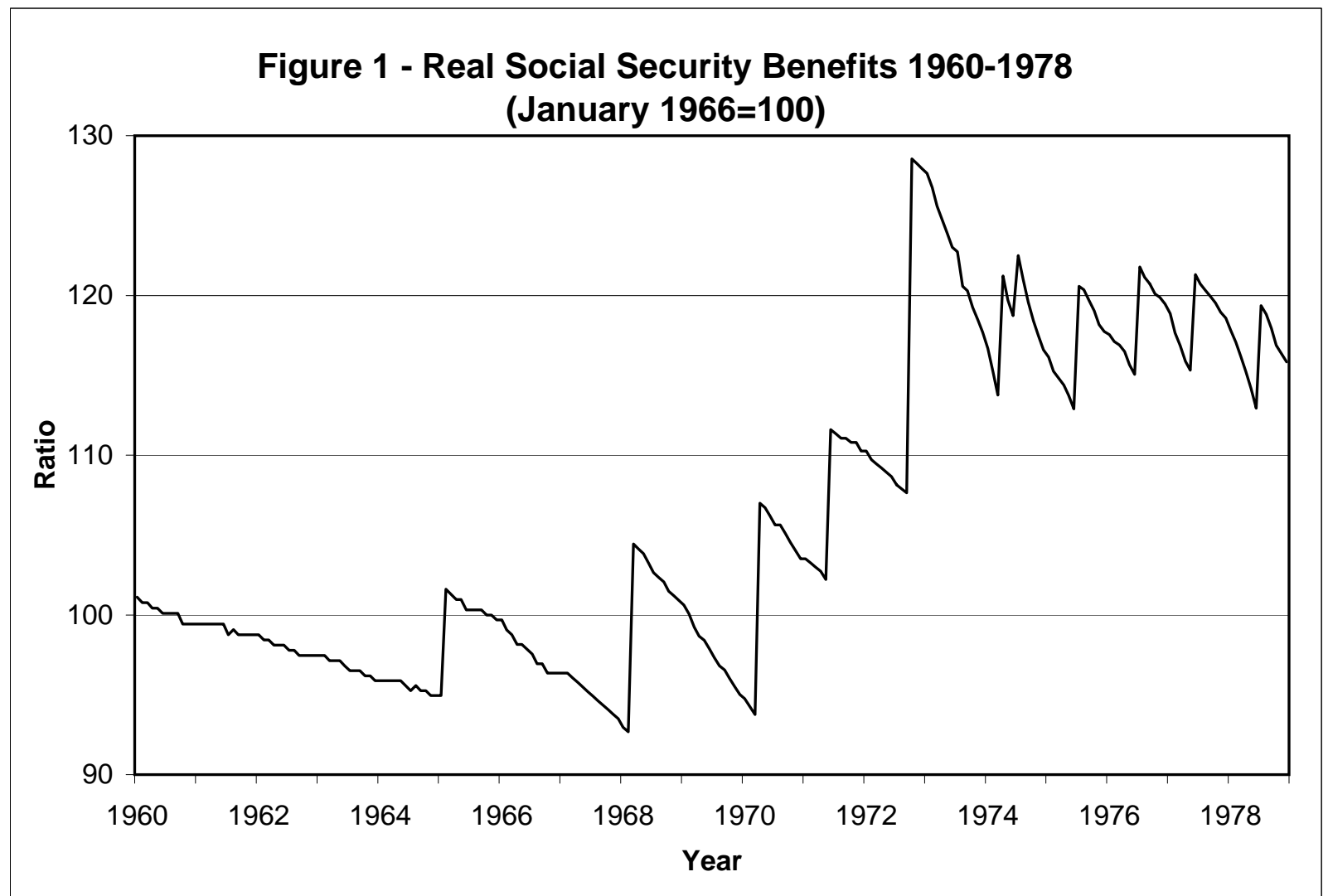

Figure 2 - Labor Force Participation Rate by Age 1955-1980

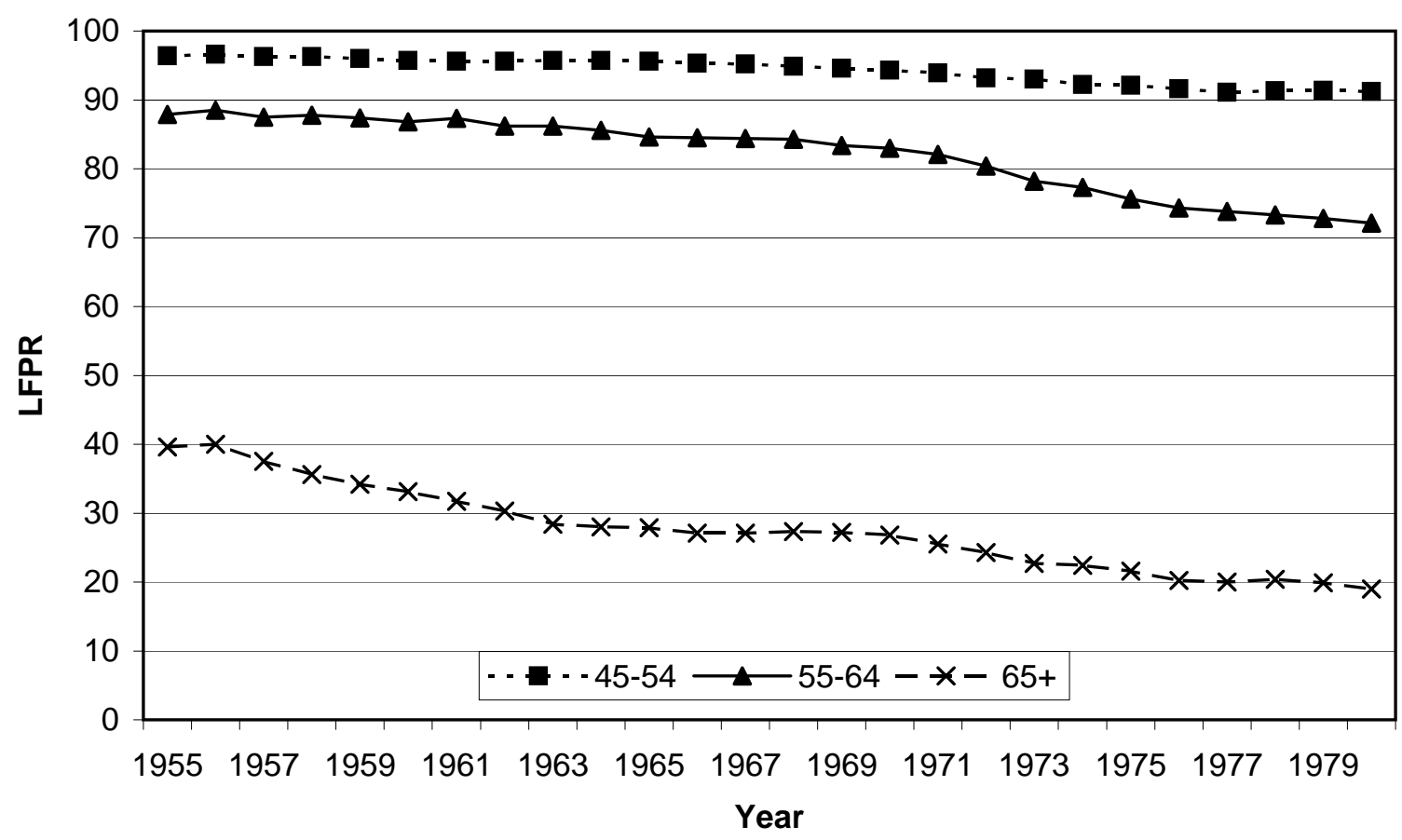




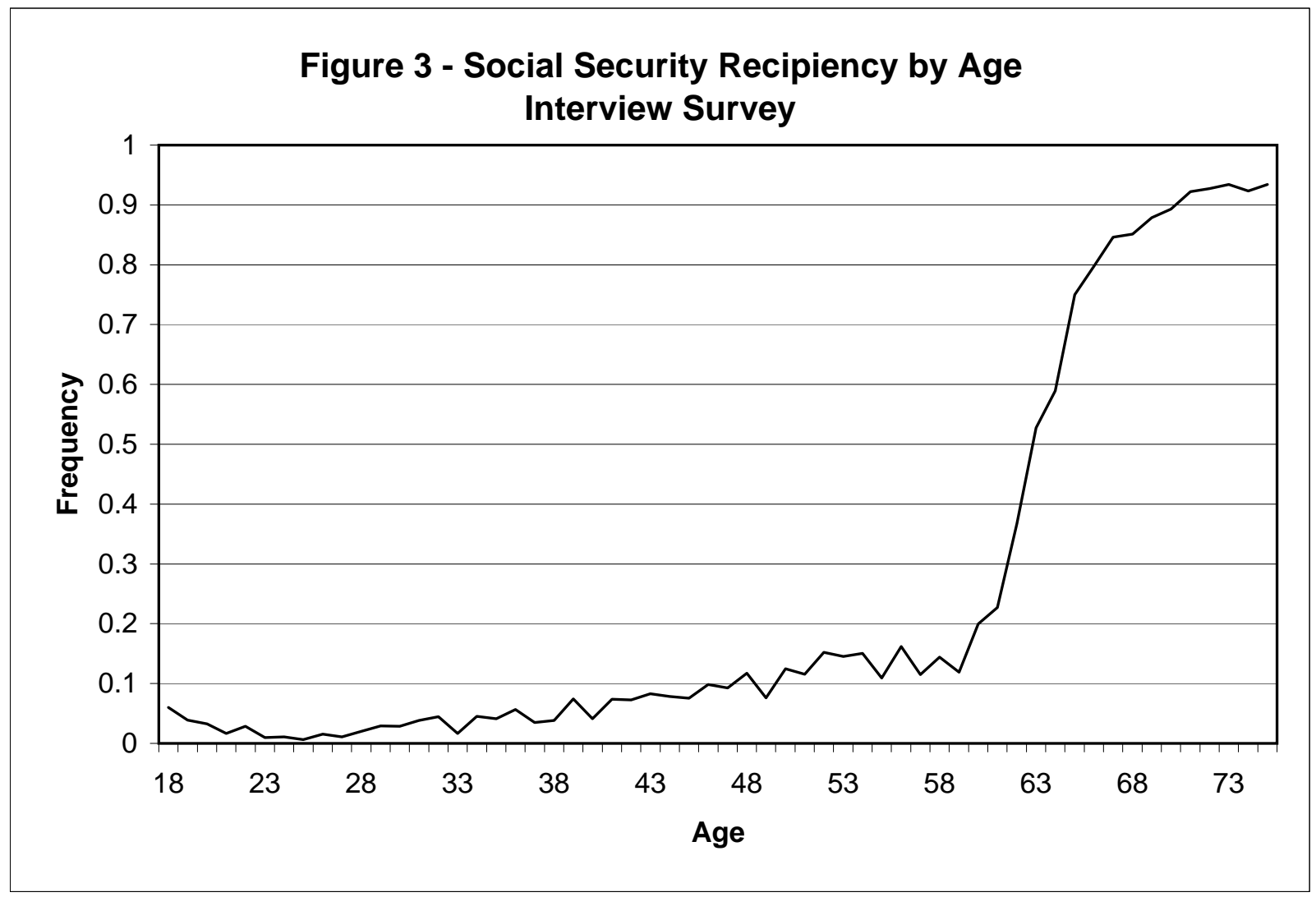

Figure 4 - Share of Households Receiving Social Security

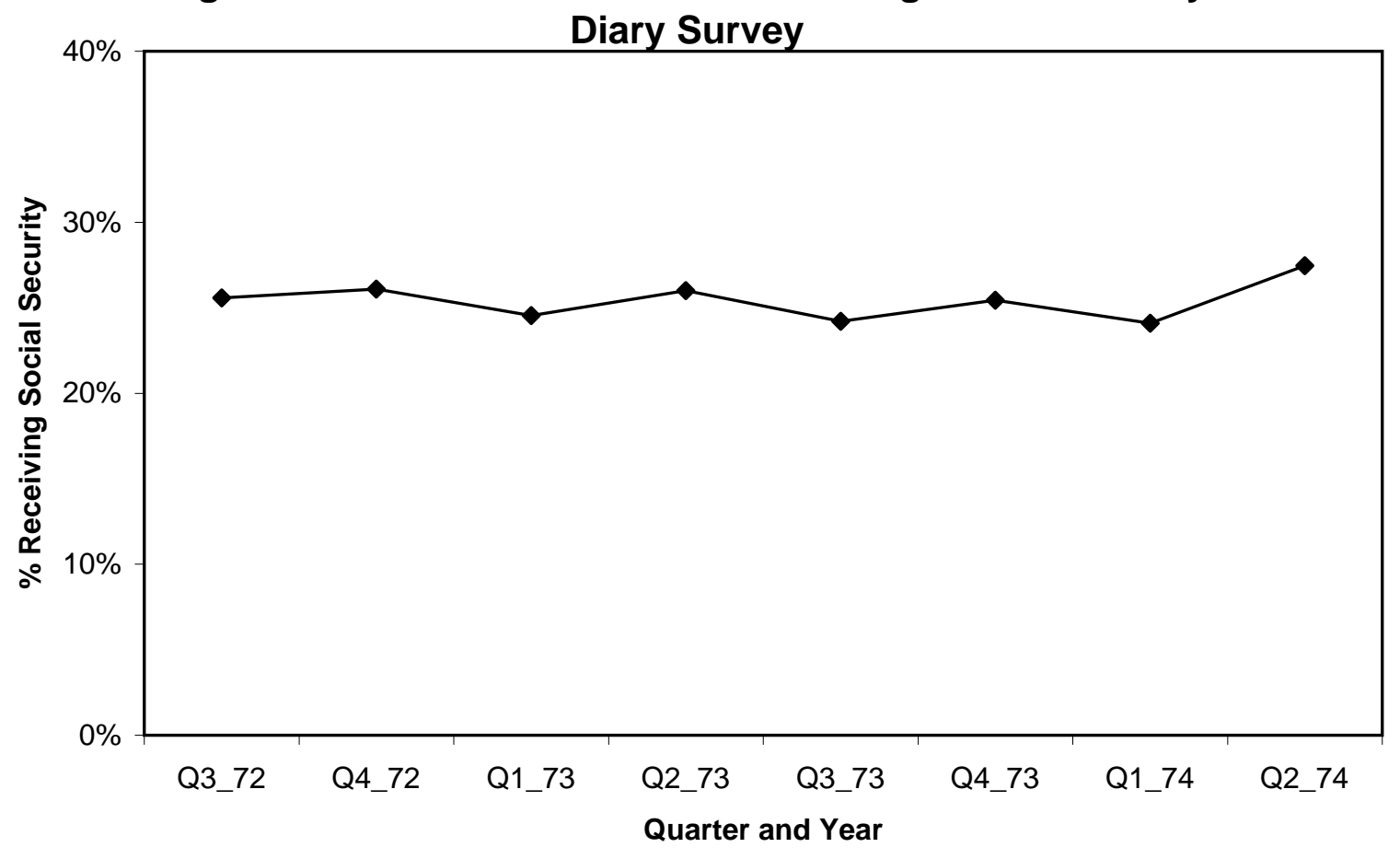




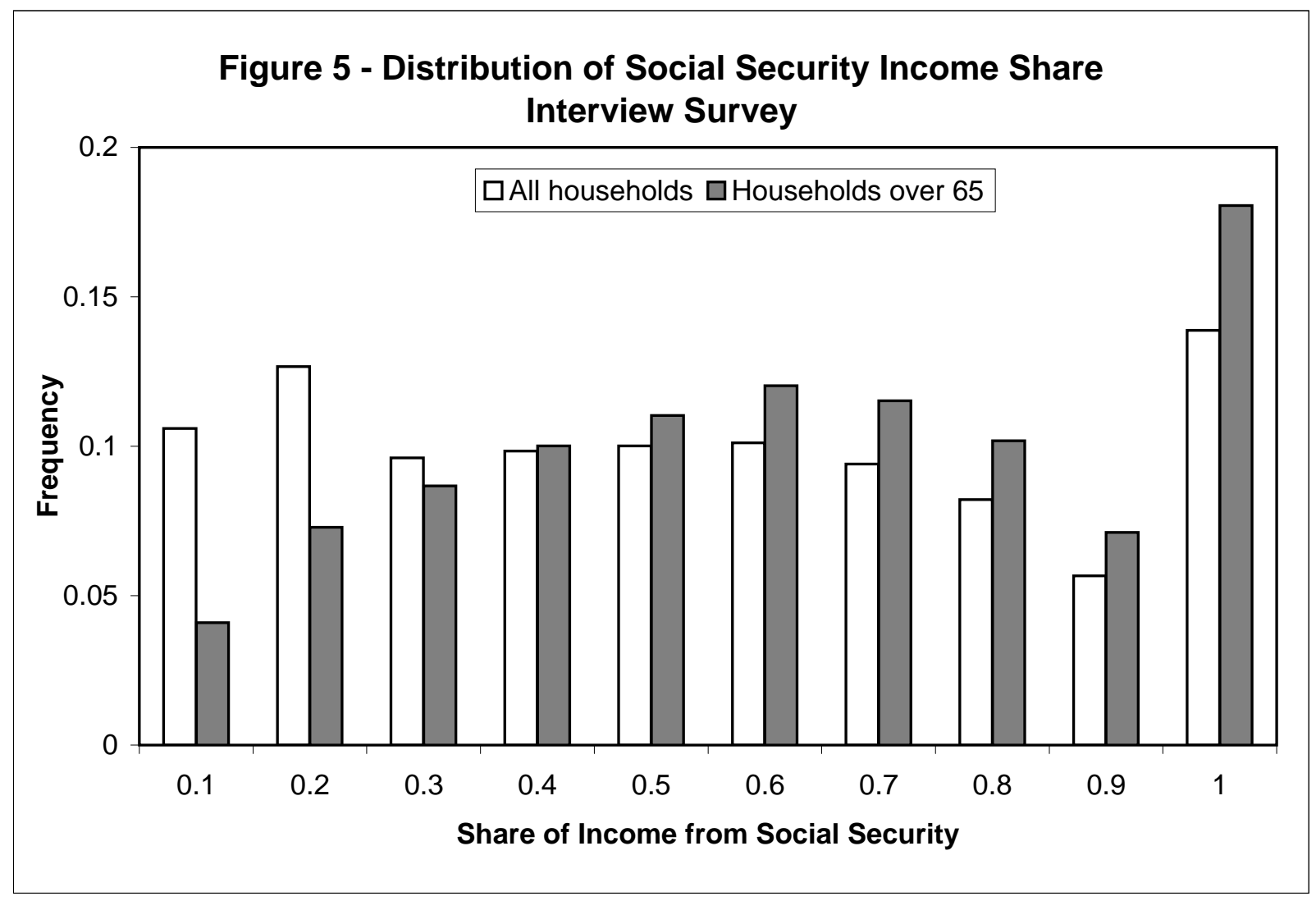



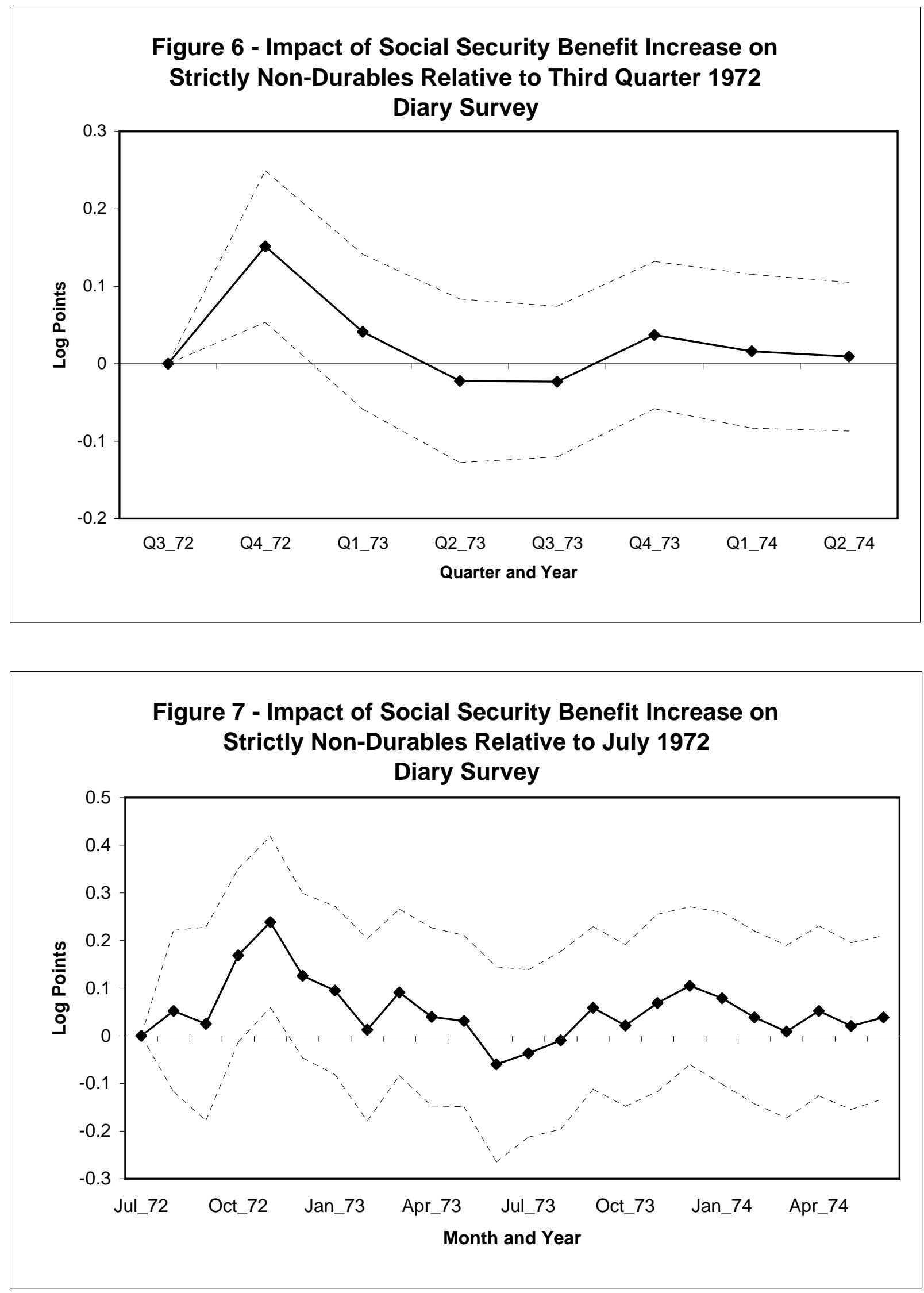

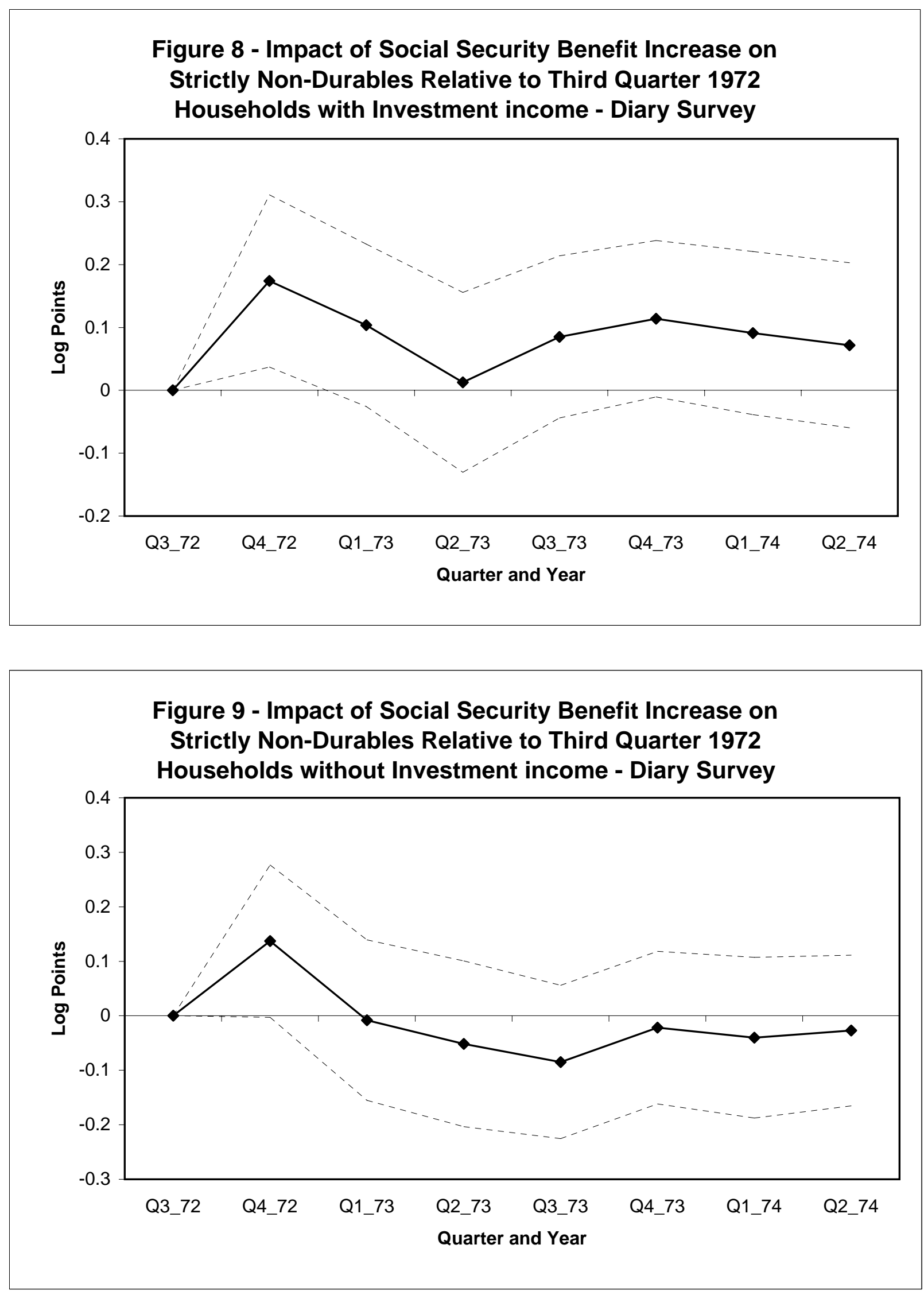

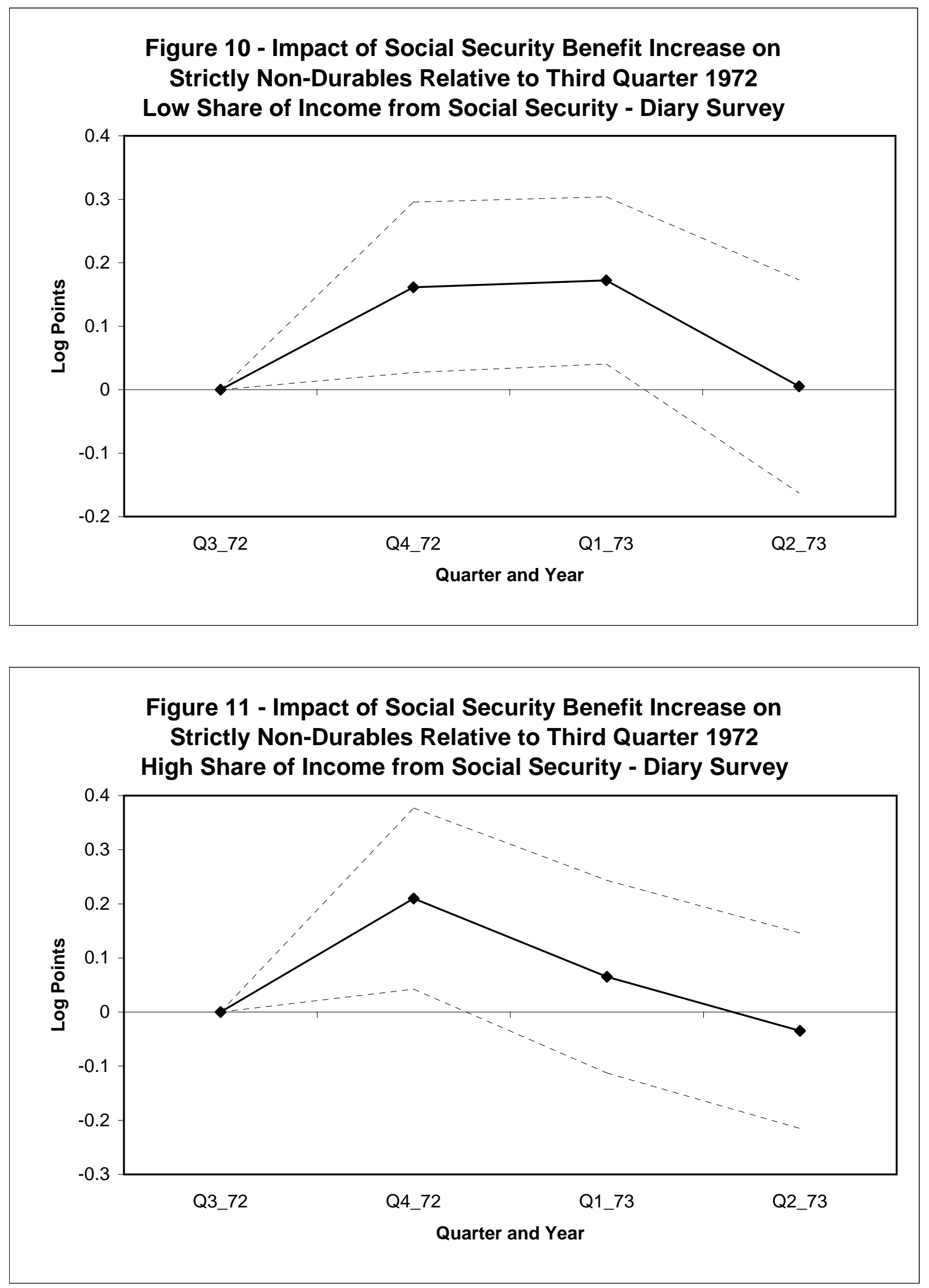

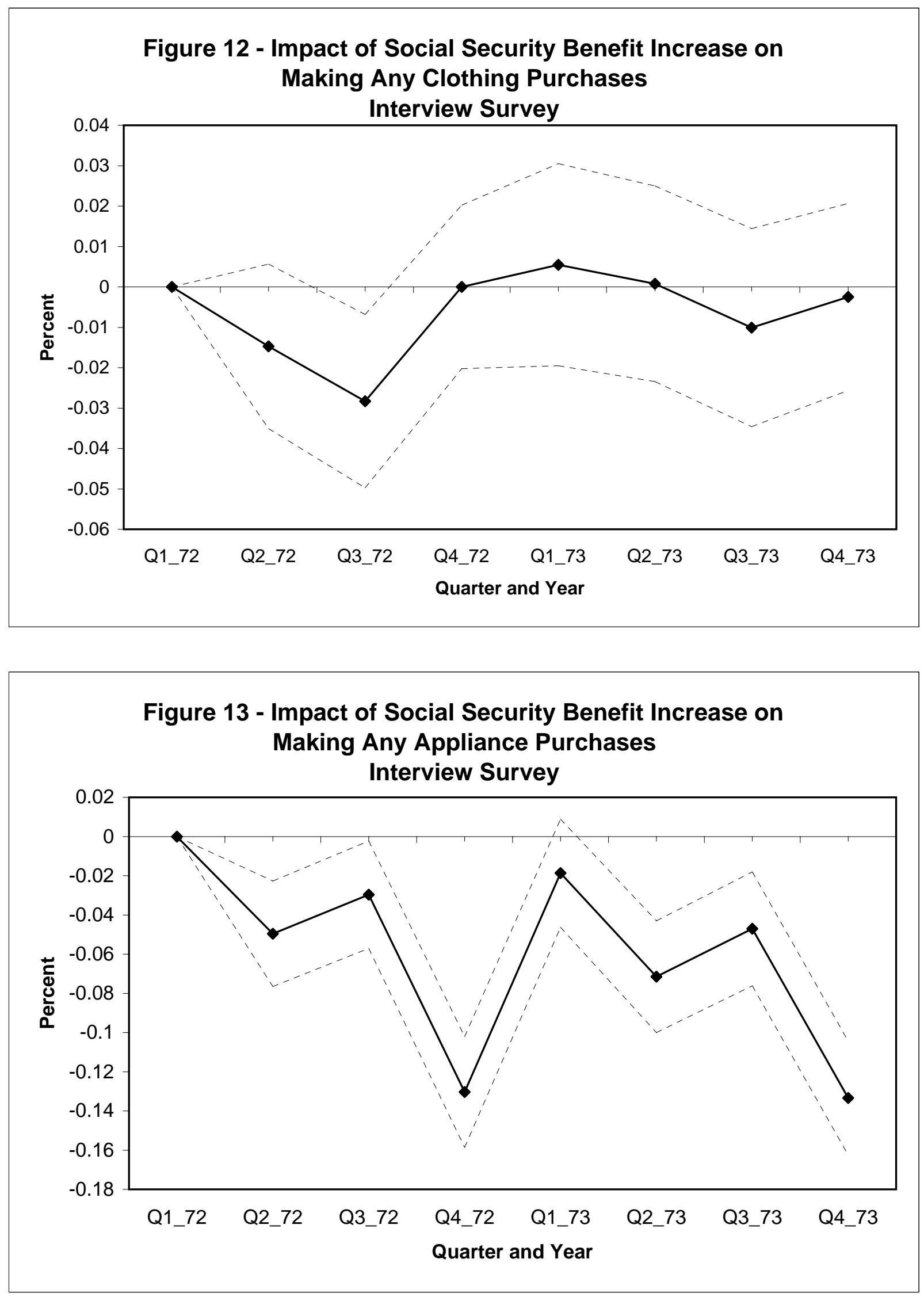


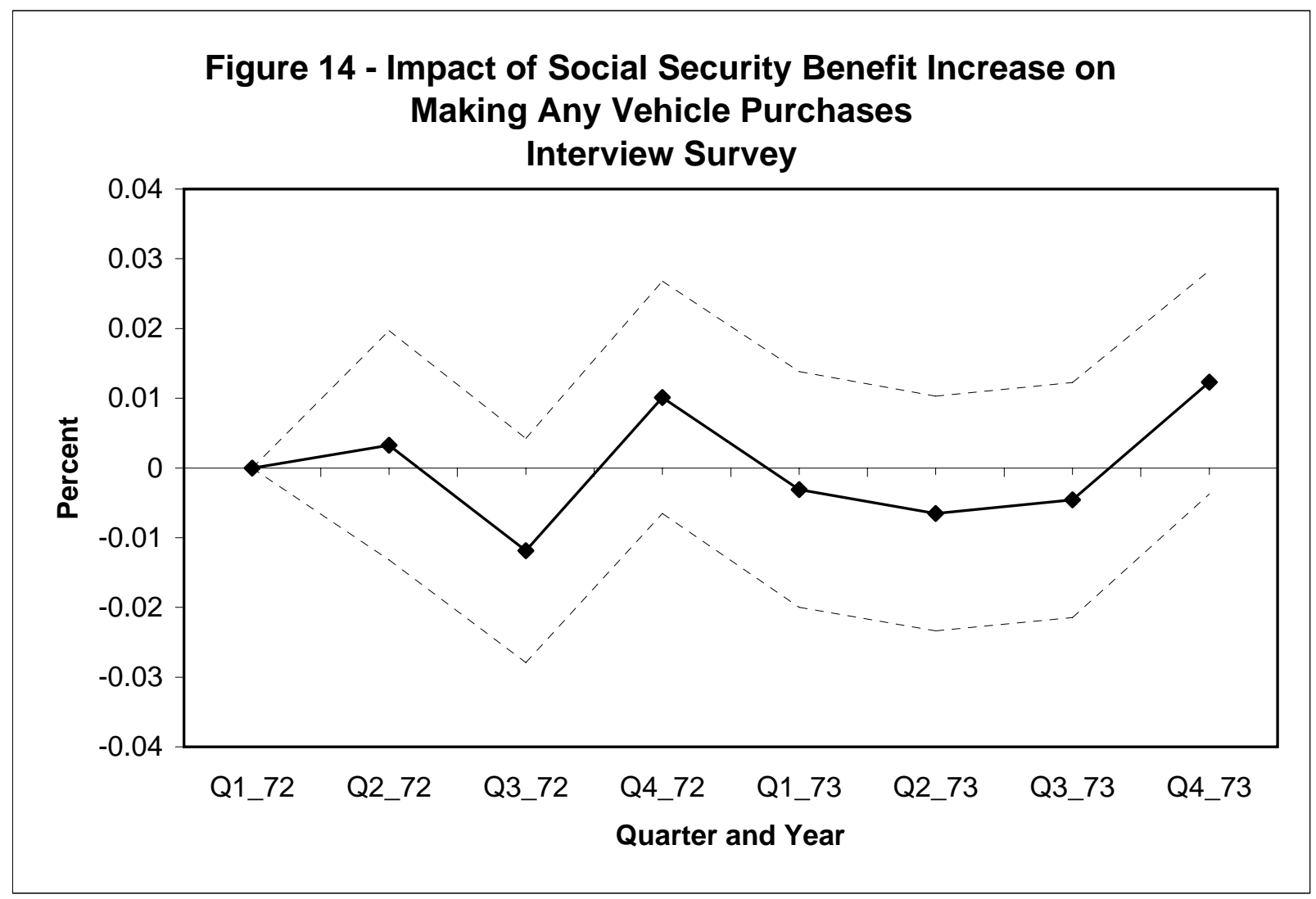

